\title{
Skin permeability and pharmacokinetics of diclofenac epolamine administered by dermal patch in Yorkshire-Landrace pigs
}

This article was published in the following Dove Press journal:

Journal of Pain Research

19 October 2012

Number of times this article has been viewed

\author{
Susanna Tse \\ Kendall D Powell ${ }^{2}$ \\ Stephen J MacLennan ${ }^{3}$ \\ Allan R Moorman ${ }^{4}$ \\ Craig Paterson ${ }^{5}$ \\ Rosonald R Bell' \\ 'Pfizer Inc, Groton, CT, USA; ${ }^{2}$ Tandem \\ Labs, Durham, NC, USA; ${ }^{3}$ BioCryst \\ Pharmaceuticals Inc, Durham, NC, \\ USA; ${ }^{4}$ Alta Vetta Pharmaceutical \\ Consulting LLC, Durham, NC, USA; \\ ${ }^{5}$ Salix Pharmaceuticals Inc, \\ Raleigh, NC, USA
}

Purpose: This study compared the pharmacokinetic profile, and systemic and local absorption of diclofenac, following dermal patch application and oral administration in YorkshireLandrace pigs.

Patients and methods: Twelve anesthetized, female, Yorkshire-Landrace pigs were randomized to receive either the dermal patch $\left(\right.$ FLECTOR $^{\circledR}$ patch, $10 \times 14 \mathrm{~cm}$; Alpharma Pharmaceuticals, a subsidiary of Pfizer Inc, New York, NY) or $50 \mathrm{mg}$ oral diclofenac (Voltaren ${ }^{\circledR}$; Novartis, East Hanover, NJ). Tissue (skin area of $2 \times 2 \mathrm{~cm}$ and underlying muscles approximately $2-3 \mathrm{~cm}$ in depth) and blood $(10 \mathrm{~mL})$ samples were collected at timed intervals up to 11.5 hours after initial patch application or oral administration. The concentrations of diclofenac in plasma, skin, and muscle samples were analyzed using validated ultra performance liquid chromatography tandem mass spectrometric methods.

Results: Peak systemic exposure of diclofenac was very low by dermal application compared with oral administration (maximum concentration $\left[\mathrm{C}_{\max }\right]$ values of $3.5 \mathrm{vs} 9640 \mathrm{ng} / \mathrm{mL}$, respectively). Absorption of diclofenac into underlying muscles beneath the dermal patch was sustained, and followed apparently zero-order kinetics, with the skin serving as a depot with elevated concentrations of diclofenac. Concentrations of diclofenac in muscles beneath the patch application site were similar to corresponding tissues after oral administration $\left(\mathrm{C}_{\max }\right.$ values of 879 and $1160 \mathrm{ng} / \mathrm{mL}$, respectively). In contrast to the wide tissue distribution of diclofenac after oral administration, dermal patch application resulted in high concentrations of diclofenac only on the treated skin and immediate tissue underneath the patch. Low concentrations of diclofenac were observed in the skin and muscles collected from untreated areas contralateral to the site of dermal patch application.

Conclusion: Dermal patch application resulted in low systemic absorption and high tissue penetration of diclofenac compared with oral administration.

Keywords: NSAIDs, systemic absorption, topical patch, tissue distribution

\section{Introduction}

Interest has been growing in topical nonsteroidal anti-inflammatory drug (NSAID) preparations, which involve direct application of the NSAID to the site of injury to mediate localized pain relief. Treatment with topical NSAIDs has been shown to provide clinically effective analgesia at the site of application while minimizing systemic absorption. ${ }^{1,2}$ The benefits associated with topical NSAIDs include: (1) avoidance of first-pass metabolism and other variables associated with the absorption of drugs through the gastrointestinal tract; (2) reduced systemic side effects; (3) ease of dose termination in the event of adverse events; (4) sustained and controlled drug delivery
Correspondence: Susanna Tse Pfizer Inc, Eastern Point Road, Groton, CT, USA

Tel + I 8607155942

Fax +l 8607156427

Email susanna.tse@pfizer.com 
over an extended period of time; (5) direct access to target site; (6) convenient administration; (7) improved patient acceptance and adherence; and (8) a viable solution for treatment when oral dosing is not possible. ${ }^{3}$

The diclofenac epolamine topical patch (FLECTOR ${ }^{\circledR}$ patch, $10 \times 14 \mathrm{~cm}$; Alpharma Pharmaceuticals, a subsidiary of Pfizer Inc, New York, NY) is a topical patch containing $1.3 \%$ diclofenac epolamine, indicated for the treatment of acute pain due to minor strains, sprains, and contusions. ${ }^{1,4-6}$ The diclofenac epolamine topical patch was found to be more effective than placebo in treating strains, sprains, and contusions, ${ }^{4,7,8}$ and symptoms of primary osteoarthritis of the knee. ${ }^{2}$ Diclofenac epolamine topical patch was also shown to be either superior or equivalent to oral diclofenac formulations or placebo for use in osteoarthritis of the knee and soft-tissue injuries. ${ }^{9}$ In clinical studies, the plasma concentrations (in the order of 1 to $3 \mathrm{ng} / \mathrm{mL}$ ) and systemic bioavailability (in the order of $\approx 1 \%$ ) of the diclofenac epolamine patch were very low compared with oral intake. ${ }^{5}$ As a result, the diclofenac epolamine topical patch was shown to be well tolerated in clinical studies, with minimal drug-related systemic adverse events. ${ }^{1,4-6}$

While the efficacy and tolerability of the diclofenac epolamine patch compared with placebo or oral formulations has been previously investigated, there is a lack of data available that directly compares the pharmacokinetic (PK) profile, systemic absorption, and local tissue penetration of the topical preparation with that of oral formulations in the same model system. In the past, pigs have been used as a model for topical drug delivery due to similar fluxes of drugs between human and pig skin. ${ }^{10}$ Therefore, the primary objective of the current study was to compare the PK profile, and systemic and local absorption of diclofenac epolamine, from a dermal patch and from oral diclofenac sodium, in Yorkshire-Landrace pigs.

\section{Methods}

\section{Animal model and experimental design}

This study was conducted in twelve adult, female, YorkshireLandrace pigs (Mark Lavallée's Farm, St Charles Borromée, Canada) weighing 16.1 to $19.2 \mathrm{~kg}$ at the onset of dosing. All animals were subject to thorough health assessments and clinical evaluations at arrival, prior to randomization, and within 24 hours of dosing. Animals were housed individually in stainless steel cages equipped with an automatic watering system, in a temperature- and humidity-controlled room $\left(21^{\circ} \mathrm{C} \pm 3^{\circ} \mathrm{C}\right.$ and relative humidity of $\left.50 \% \pm 20 \%\right)$, and under a 12-hour light/12-hour dark cycle. A standard, certified, commercial chow (Teklad Certified Miniswine
Diet \#7037C; Harlan Laboratories Inc, Indianapolis, IN) was provided to the animals twice daily, except during the study procedures. Water (municipal tap water, which had been exposed to ultraviolet light and purified by reverse osmosis) was available to the study animals ad libitum, except during the study procedures. Animals underwent a 6- to 9-day acclimatization period prior to the start of any experimental procedures. The care of the laboratory animals was in accordance with national and international guidelines.

\section{Study design and experimental procedures}

Following an overnight fast, animals were randomized to receive either a single application of a dermal patch containing $1.3 \%$ diclofenac epolamine (FLECTOR ${ }^{\circledR}$ Patch $10 \times 14 \mathrm{~cm})(\mathrm{n}=6$; group 1$)$ or 50-mg oral diclofenac sodium (Voltaren $^{\circledR}$; Novartis, East Hanover, NJ) ( $\mathrm{n}=6$; group 2). Animals fasted overnight prior to the day of dosing.

On the day of dosing, the animals were anesthetized with isoflurane gas, and remained under isoflurane anesthesia for the entire dosing and sample collection period. Animals were intubated, and placed on a ventilator supplemented with oxygen (rate: 10-15 breaths/min, pressure: 15-30 cm $\mathrm{H}_{2} \mathrm{O}$ ), or manually ventilated to maintain oxygenation. Local anesthetic (lidocaine spray, 10\% w/w) was applied to the glottis before intubation. Intravenous fluid therapy was given throughout the anesthesia (sterile Lactated Ringer's solution at a rate of $100 \mathrm{~mL} / \mathrm{h}$ ), and body temperature was maintained at approximately $37^{\circ} \mathrm{C}$ by placing the animals on a heating pad, and monitored during the experimental procedure using a rectal thermometer. Prior to the application of the patch, the animals were sedated using a mixture of ketamine $(21.8 \mathrm{mg} / \mathrm{kg})$ and acepromazine $(0.22 \mathrm{mg} / \mathrm{kg})$, administered by intramuscular injection.

\section{Treatment}

In the animals randomized to group 1, the right- and leftdorsal back of each animal was shaved and cleaned using sterile water prior to dermal patch application. Each patch was divided into six equal pieces (approximately $5.0 \times 4.7 \mathrm{~cm}$ ) and applied to the lower right-dorsal region of the animal in a longitudinal direction, parallel to the spine such that the final area covered by the six pieces was the same size as the original patch $(10.0 \times 14.0 \mathrm{~cm})$. A schematic for the placement of the dermal patch and the sampling locations for animals in group 1 (dermal treatment) is depicted in Figure 1A.

Following confirmation of anesthesia, diclofenac was administered orally to the animals in group 2 as follows: 
A

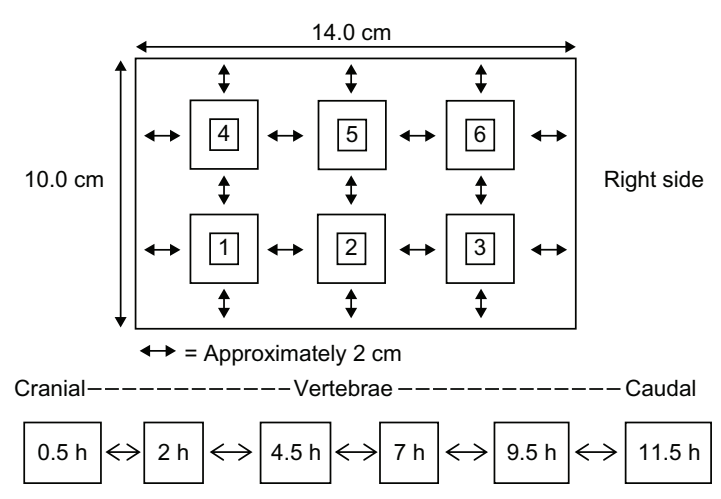

B

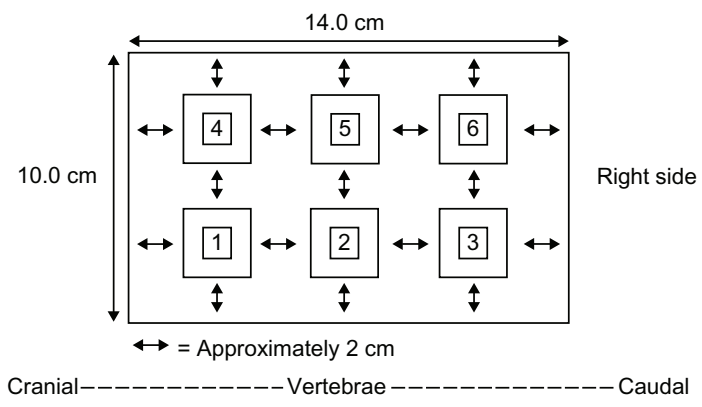

Pre-

dosing

Figure I Schematic for the placement of the dermal patch (divided into six pieces) and sampling for animals in group I (dermal treatment group) (A) and group 2 (oral treatment group) (B).

Note: Samples were collected randomly from the six identified sites.

an endoscope was advanced into the gastrointestinal tract of each animal until it was positioned immediately in front of the pylorus; once the pylorus was centered in the field of vision, the distal segment of the endoscope was inserted into the duodenum; a diclofenac tablet was then released into the duodenum and the duodenum flushed with approximately $20 \mathrm{~mL}$ of reverse osmosis water.

\section{Skin and muscle sampling}

In group 1 animals, full-thickness skin and muscle samples were collected from the dermal patch site (right-dorsal side) at $0.5,2,4.5,7,9.5$, and 11.5 hours post-application. Skin and muscle biopsies were also taken from the left-dorsal side of each animal (as depicted in Figure 1A) before application of the patch, and at 2, 7, and 11.5 hours post-application.

At each time point one piece of dermal patch was removed and the skin cleaned to remove any residual adhesive present, and then skin/subcutis and epaxial lumbar muscle samples (approximately $2 \times 2 \mathrm{~cm}$ and $2-$ to $3-\mathrm{cm}$ depth) were removed from the appropriate site using sterile surgical equipment. Special attention was paid to minimize any cross contamination between the skin/subcutis and the muscle samples by using separate equipment for each skin/ subcutis sample and muscle sample. Following excision of the tissue sample, the removed piece of dermal patch was reapplied as closely as possible to the original site. Each skin/ subcutis or muscle sample was trimmed and weighed, and stored frozen until later homogenized for analysis.

In animals from group 2, collection of skin and muscle samples was performed using a grid $(14 \times 10 \mathrm{~cm})$ marked on the right-dorsal lumbar area prior to oral administration of diclofenac. A schematic for the sampling locations for animals in group 2 (oral treatment) is depicted in Figure 1B. As with the animals in group 1, skin/subcutis and epaxial lumbar muscle samples of approximately $2 \times 2 \mathrm{~cm}$ and 2 to $3-\mathrm{cm}$ depth were removed from the sampling locations using sterile surgical equipment. Each biopsy site was evenly spaced from one another by approximately $2 \mathrm{~cm}$. Samples were taken predose (on the left-dorsal side), and at $0.5,2,4.5,7,9.5$, and 11.5 hours postdose (on the rightdorsal side).

\section{Tissue sample homogenization, extraction,} and ultra performance liquid chromatography tandem mass spectrometric analyses

Skin samples were homogenized using a FastPrep 24 tissue homogenizer (MP Biomedicals Inc, Santa Ana, CA) after incubation with $0.1 \mathrm{M}$ sodium hydroxide for 24 hours at $60^{\circ} \mathrm{C}$. Muscle samples were homogenized using a FastPrep 24 tissue homogenizer, following the addition of aqueous $25 \%$ acetonitrile with $0.001 \mathrm{M}$ sodium hydroxide. Diclofenac in the tissue homogenates was extracted by a liquid-liquid extraction method using ethyl acetate as the extraction solvent, after the addition of hydrochloric acid in water $(0.1 \mathrm{M}$ for skin samples or $0.01 \mathrm{M}$ for muscle samples) and an internal standard solution (diclofenac- $\mathrm{d}_{4}$ in $50 \%$ aqueous dimethyl sulfoxide). The ethyl acetate extracts were transferred into clean tubes, evaporated to dryness, and reconstituted with $0.1 \mathrm{~mL}$ of $50 \%$ aqueous dimethyl sulfoxide, then transferred to autosampler vials and analyzed for diclofenac concentrations.

The concentrations of diclofenac in skin and muscle extracts were measured using an ultra performance liquid chromatographic system (Acquity UPLC ${ }^{\circledR}$, Waters Corporation, Milford, MA) equipped with a triple quadrupole tandem mass spectrometer (API 5000 ${ }^{\mathrm{TM}}$ AB Sciex LLC, Foster City, CA). Separation of diclofenac was accomplished using a Waters BEH C18 column $(2.1 \times 100 \mathrm{~mm}, 1.7 \mu \mathrm{m})$ operated at $50^{\circ} \mathrm{C}$. The mobile phase consisted of $5 \mathrm{mM}$ ammonium bicarbonate with $0.01 \%$ formic acid and $5 \%$ methanol in water 
(mobile phase A), and 100\% methanol (mobile phase B). The analysis was performed under isocratic conditions $(55 \% \mathrm{~B})$ with a flow rate of $0.600 \mathrm{~mL} / \mathrm{min}$. Mass spectrometric detection of diclofenac (mass transition $296.0 \rightarrow 213.9 \mathrm{amu}$ ) and its internal standard (diclofenac- $\mathrm{d}_{4}$ : mass transition $300.1 \rightarrow 213.9$ amu) were achieved using multiple reaction monitoring under Positive Ion TurboIonSpray ${ }^{\mathrm{TM}}$ mode, using the Analys ${ }^{\circledR}$ data acquisition software version 1.4.2 (AB Sciex LLC).

In anticipation of the different concentration ranges in the skin and muscle samples with the different treatments, two separate calibration ranges were established for the measurement of diclofenac in skin and muscle homogenates. The "low-level methods" had calibration ranges of 0.0075 to $7.50 \mathrm{ng} / \mathrm{mL}$ and 0.00075 to $0.75 \mathrm{ng} / \mathrm{mL}$ for skin and muscle homogenates, respectively. The "highlevel methods" had calibration ranges of 2.00 to $2000 \mathrm{ng} / \mathrm{mL}$ and 1.00 to $1000 \mathrm{ng} / \mathrm{mL}$ for skin and muscle homogenates, respectively.

\section{Plasma sampling and diclofenac analyses}

Blood samples, collected into tubes containing tripotassium ethylenediaminetetraacetic acid as an anticoagulant, were obtained from all animals via a catheter surgically inserted into the right femoral vein or via venipuncture in the left jugular vein. In both groups 1 and 2, $10 \mathrm{~mL}$ blood samples were collected predose, and at $0.5,2,4.5,7,9.5$, and 11.5 hours postdose, and plasma samples were obtained by centrifugation. A $0.5 \mathrm{~mL}$ aliquot of the plasma sample was extracted with ethyl acetate after the addition of hydrochloric acid $(1 \mathrm{~N})$ and internal standard solution (diclofenac- $\mathrm{d}_{4}$ in $50 \%$ dimethyl sulfoxide). The plasma ethyl acetate extracts were processed using similar methods to those used for tissue homogenate extracts.

Plasma concentrations of diclofenac were determined using a validated ultra performance liquid chromatography tandem mass spectrometric method with the same conditions as described for the tissue homogenate analyses. The plasma assay had a calibration curve range of 0.001 to $1.00 \mathrm{ng} / \mathrm{mL}$. Samples above the quantitation limit were diluted into the calibration range with control pig plasma.

All the bioanalytical methods (skin and muscle homogenates, low- and high-level methods, and plasma) were validated according to established best practices for bioanalytical method validation. ${ }^{11-14}$ Bioanalytical analyses were carried out according to the acceptance criteria outlined in the conference reports and white papers published as a result of the American Association of Pharmaceutical Scientists/Food and Drug Administration Bioanalytical Workshops. ${ }^{12}$

\section{Pharmacokinetc and statistical analysis}

The estimated PK parameters included maximum tissue/ plasma drug concentration $\left(\mathrm{C}_{\max }\right)$, time at which $\mathrm{C}_{\max }$ was first observed $\left(\mathrm{T}_{\max }\right)$, and area under the tissue/plasma drug concentration-time curve from 0 to 11.5 hours $\left(\mathrm{AUC}_{0-11.5 \mathrm{~h}}\right)$. Mean plasma or tissue concentration data for diclofenac over time are also presented. The PK parameters of diclofenac in plasma, skin, and muscle from individual pigs were calculated using a noncompartmental approach in WinNonlin (version 6.1, Pharsight Corporation, Mountainview, CA). Mean PK parameters were calculated using Excel 2007 (Microsoft Corporation, Redmond WA). The AUC values were estimated using the linear trapezoidal rule. ${ }^{15}$ Data are presented as mean and standard deviation (SD) for each treatment group. No statistical analyses were conducted on data obtained in this study.

\section{Results}

\section{Bioanalytical method performance}

The analytical performance (precision and accuracy) of the bioanalytical methods for the determination of diclofenac in skin and muscle homogenates, and in plasma samples, was assessed by the overall bias and coefficient of variation values of the quality control samples analyzed with each batch of study samples. The analytical performance results are summarized in Table 1. The average percent bias and percent coefficient of variation for the measurement of diclofenac were within $\pm 10 \%$ for all five methods used in analyzing tissue and plasma samples from this study; this indicated that diclofenac was measured with a high degree of precision and accuracy despite the very low concentrations (ie, low $\mathrm{pg} / \mathrm{mL}$ ) in some samples (eg, very low plasma concentrations in the dermal treatment group and low skin concentrations in the oral treatment group) and the wide range of concentrations observed between the two treatment groups.

\section{PK profile of diclofenac in plasma, skin, and muscle} after oral or dermal administration

The mean PK parameters of diclofenac in plasma, skin, and muscle after oral or dermal administration are shown in Table 2. In animals treated with the dermal patch, the mean $\mathrm{T}_{\max }$ was observed at 5.3, 6.7, and 5.2 hours in plasma, treated muscle, and treated skin, respectively. In animals that received the oral dose, the mean $\mathrm{T}_{\max }$ was observed at 2 hours in the plasma and muscle, and at 3.3 hours in the skin. 
Table I Analytical performance of the UPLC/MS-MS methods used for the analyses of diclofenac in tissue homogenates and plasma samples from Yorkshire-Landrace pigs

\begin{tabular}{|c|c|c|c|c|c|c|}
\hline & \multicolumn{3}{|c|}{ Skin homogenate (low level) } & \multicolumn{3}{|c|}{ Muscle homogenate (low level) } \\
\hline & Low QC & Mid QC & High QC & Low QC & Mid QC & High QC \\
\hline $\mathrm{QC}$ concentration $(\mathrm{ng} / \mathrm{mL})$ & 0.0225 & 0.570 & 5.70 & 0.00225 & 0.0225 & 0.570 \\
\hline Average $\%$ bias & -4.9 & -6.8 & -8.4 & -0.9 & 9.3 & -2.1 \\
\hline$\% \mathrm{CV}$ & 4.0 & 3.8 & 2.0 & 6.6 & 8.0 & 3.4 \\
\hline \multirow[t]{3}{*}{$n$} & 4 & 4 & 4 & 4 & 4 & 4 \\
\hline & \multicolumn{3}{|c|}{ Skin homogenate (high level) } & \multicolumn{3}{|c|}{ Muscle homogenate (high level) } \\
\hline & Low QC & Mid QC & High QC & Low QC & Mid QC & High QC \\
\hline $\mathrm{QC}$ concentration $(\mathrm{ng} / \mathrm{mL})$ & 6.0 & 60.0 & 1500 & 3.0 & 30.0 & 750 \\
\hline Average $\%$ bias & -4.0 & -1.8 & -4.0 & 1.3 & 3.7 & 2.3 \\
\hline$\% \mathrm{CV}$ & 4.2 & 1.3 & 1.7 & 6.4 & 8.0 & 4.4 \\
\hline \multirow[t]{3}{*}{$\mathrm{n}$} & 8 & 8 & 8 & 8 & 8 & 8 \\
\hline & \multicolumn{6}{|l|}{ Plasma } \\
\hline & Low QC & Mid QC & High QC & Dilution QC I & Dilution QC 2 & Dilution QC 3 \\
\hline $\mathrm{QC}$ concentration $(\mathrm{ng} / \mathrm{mL})$ & 0.003 & 0.050 & 0.750 & 10.0 & 10.0 & 1000 \\
\hline Average \% bias & -2.3 & 1.4 & -5.5 & -8.8 & -5.4 & 6.0 \\
\hline$\% \mathrm{CV}$ & 6.9 & 4.0 & 6.0 & 2.8 & 2.5 & 4.5 \\
\hline $\mathrm{n}$ & 16 & 16 & 16 & 4 & 4 & 4 \\
\hline
\end{tabular}

Abbreviations: UPLC/MS-MS, ultra performance liquid chromatography tandem mass spectrometric; QC, quality control; CV, coefficient of variation.

Systemic and local absorption of diclofenac by dermal or oral administration

After a 50-mg oral dose of diclofenac was administered to Yorkshire-Landrace pigs, the mean $( \pm \mathrm{SD})$ plasma $\mathrm{C}_{\max }$ was $9640( \pm 906) \mathrm{ng} / \mathrm{mL}$ (Table 2). Maximum concentrations were achieved at 2 hours $\left(\mathrm{T}_{\max }\right)$ after oral dosing. The mean $( \pm \mathrm{SD}) \mathrm{AUC}_{0-11.5 \mathrm{~h}}$ was $46,000( \pm 4817) \mathrm{ng} \cdot \mathrm{h} / \mathrm{mL}$. The PK of oral diclofenac observed in this study are similar to those reported in Yucatan miniature pigs given a $50-\mathrm{mg}$ oral dose of diclofenac. ${ }^{16}$

Systemic absorption of diclofenac, as assessed by $\mathrm{C}_{\max }$ and $\mathrm{AUC}$, was lower following administration by dermal patch compared with oral dosing (dermal/ oral $\mathrm{C}_{\max }$ ratio: 0.0004; dermal/oral AUC ratio: 0.0005) (Table 2; Figure 2A). Systemic availability following dermal patch administration was also subject to greater variability than oral administration.

In the right-dorsal muscles, similar concentrations of diclofenac were achieved in animals by either the dermal or oral route of administration (dermal/oral $\mathrm{C}_{\max }$ ratio: 0.76; dermal/oral AUC ratio: 0.70) (Table 2 and Figure 2B). The exposure to diclofenac was greater in skin biopsies from the right-dorsal patch application sites than in biopsies obtained following oral administration (dermal/oral $\mathrm{C}_{\max }$ ratio: 12.8; dermal/oral AUC ratio: 16.8) (Table 2 and Figure 2C). In the dermal treatment group, the muscle to skin concentration ratios on the right side were more or less constant between 0.5 and 11.5 hours (Figure 3), suggesting that the dermal absorption of diclofenac was sustained and followed apparent zero-order kinetics, with the diclofenac absorbed into the

Table 2 PK parameters of diclofenac in female Yorkshire-Landrace pigs following oral administration or dermal patch application

\begin{tabular}{|c|c|c|c|c|c|c|c|c|c|c|}
\hline \multirow[t]{2}{*}{ Route } & \multirow[t]{2}{*}{ Matrix (side) } & \multicolumn{3}{|c|}{$\begin{array}{l}\mathrm{C}_{\max } \\
\text { (ng/mL or } n g / g)\end{array}$} & \multicolumn{3}{|l|}{$\begin{array}{l}T_{\max } \\
\text { (h) }\end{array}$} & \multicolumn{3}{|c|}{$\begin{array}{l}\left.\text { AUC }_{(0-11.5} \mathrm{h}\right) \\
(\mathrm{ng} \cdot \mathrm{h} / \mathrm{mL} \text { or } \mathrm{ng} \cdot \mathrm{h} / \mathrm{g})\end{array}$} \\
\hline & & Mean & SD & $\bar{n}$ & Mean & SD & $\bar{n}$ & Mean & SD & $\bar{n}$ \\
\hline \multirow[t]{3}{*}{ Oral } & Plasma & 9640 & 906 & 6 & 2 & 0 & 6 & 46,000 & 4817 & $\overline{6}$ \\
\hline & Muscle & 1160 & 256 & 6 & 2 & 0 & 6 & 5867 & 1455 & 6 \\
\hline & Skin & 1500 & 319 & 6 & 3.3 & 1.4 & 6 & 9600 & 1817 & 6 \\
\hline \multirow[t]{5}{*}{ Dermal } & Plasma & 3.49 & 5.57 & 6 & 5.3 & 5 & 6 & 25.2 & 39.0 & 6 \\
\hline & Muscle (treated) & 879 & 632 & 6 & 6.7 & 4.2 & 6 & 4117 & 2633 & 6 \\
\hline & Muscle (untreated) & 0.652 & 0.926 & 6 & 4.2 & 3.2 & 6 & 5.0 & 6.7 & 6 \\
\hline & Skin (treated) & 19,200 & 2350 & 6 & 5.2 & 3 & 6 & 161,167 & 24,333 & 6 \\
\hline & Skin (untreated) & 2.4 & 2.51 & 6 & 4.2 & 3.2 & 6 & 14.3 & 15.6 & 6 \\
\hline
\end{tabular}

Notes: Treated: dermal patch applied to the right-dorsal lumbar region; untreated: samples obtained but no patch was administered.

Abbreviations: PK, pharmacokinetic; $\mathrm{C}_{\max }$, highest drug concentration observed in plasma/tissues; $\mathrm{T}_{\max }$, time at which $\mathrm{C}_{\max }$ was first observed; $A \cup \mathrm{C}_{(0-11.5 \mathrm{~h})}$, area under the plasma/tissue drug concentration-time curve for 0-11.5 hours. 

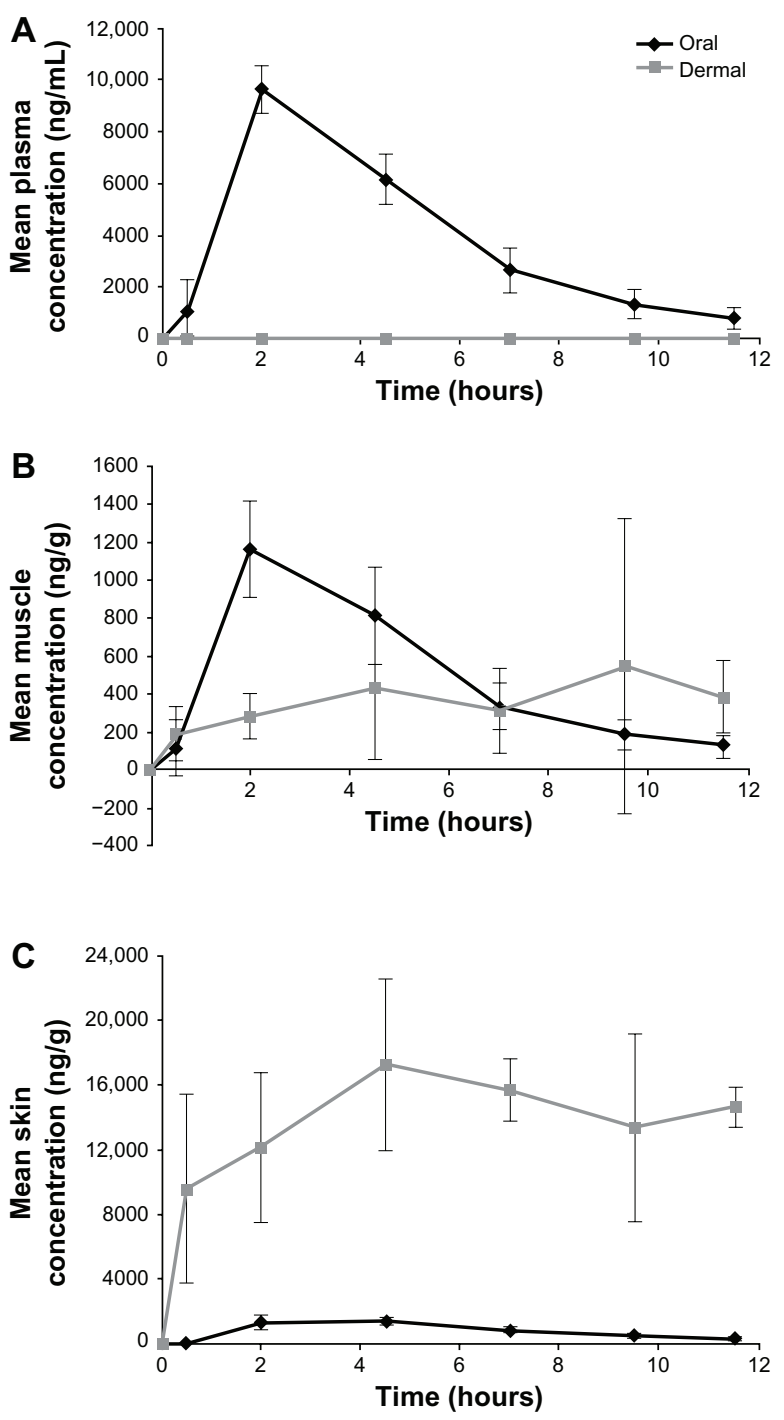

Figure 2 Diclofenac concentrations in the plasma (A), muscle (B), and skin (C) of female Yorkshire-Landrace pigs following oral administration or dermal patch application.

skin serving as a depot to deeper tissue layers such as the muscles.

Following oral administration, skin diclofenac concentrations were similar to those recorded in muscle samples. However, unlike the wide tissue distribution of diclofenac after oral administration, high concentrations of diclofenac were only observed in skin and muscle samples on the right-dorsal (treated) side, whereas very low concentrations were observed in tissues from the left-dorsal (untreated) side. The differences in tissue concentrations between the treated and untreated sides demonstrate that diclofenac was absorbed locally from the dermal patch and penetrated to the underlying muscle layer, with minimal distribution to other tissues beyond the application site.

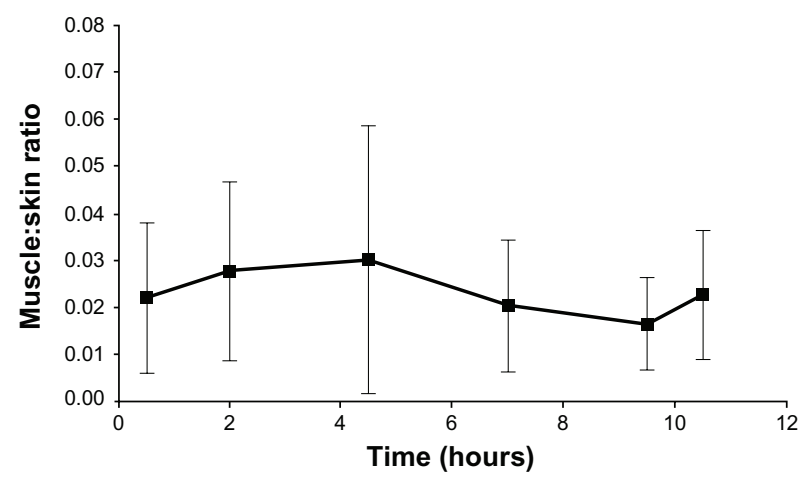

Figure 3 Muscle to skin concentration ratios of diclofenac after the application of dermal patch in Yorkshire-Landrace pigs.

\section{Discussion}

This study was conducted to compare the PK of diclofenac by dermal versus oral administration in the same experimental model. The systemic and local absorption of diclofenac administered by a diclofenac epolamine $1.3 \%$ patch and oral diclofenac sodium (50-mg single oral dose) were evaluated in Yorkshire-Landrace pigs. Due to the morphological and physiological similarities between human and porcine skin, and the general comparative biology between humans and pigs, the Yorkshire-Landrace pig is a robust model for the evaluation of dermal absorption. ${ }^{10,17}$

The results showed very low systemic exposures of diclofenac when administered by dermal patch compared with oral administration. Plasma concentrations (mean $\mathrm{C}_{\text {max }} \approx 3.5 \mathrm{ng} / \mathrm{mL}$ by dermal patch) obtained in this study are comparable with those reported in healthy human subjects ${ }^{5}$ and, therefore, confirm the suitability of this animal model. Steady-state plasma diclofenac concentrations in studies of healthy human subjects were achieved before day 3 of patch administration ( 2 patches/day; $\mathrm{t}_{1 / 2}$ 9-12 hours) and were approximately 1 to $3 \mathrm{ng} / \mathrm{mL} .^{5}$ In healthy human volunteers, the $\mathrm{C}_{\max }$ values observed between 0 and 12 hours following twice-daily 180-mg diclofenac epolamine patch application for four consecutive days was $1.55 \mathrm{ng} / \mathrm{mL} .{ }^{18}$ Peak plasma concentrations of diclofenac following patch application have been reported to be $0.2 \%$ to $8.0 \%$ of those observed following oral dosing. ${ }^{5,19}$

Low systemic exposure to topical diclofenac is of clinical importance since it may result in reduced rates of dosedependent NSAID-associated risks, such as gastrointestinal and cardiovascular events. ${ }^{1}$ Topical NSAID preparations must effectively penetrate the stratum corneum of the skin to reach their site of action in the underlying musculoskeletal soft tissue and peripheral nerves. ${ }^{1}$ More importantly, concentrations of diclofenac in underlying tissues following 
topical administration have not been measured successfully in clinical studies. Therefore, it is not clear whether the concentrations of diclofenac in deeper layers (eg, muscles) beneath the epidermis are due to direct penetration from the patch, or delivered via systemic circulation. ${ }^{20}$ This study provides direct evidence of the absorption and tissue penetration of diclofenac from the dermal application site to the underlying tissues.

Data from the current study demonstrated the successful dermal absorption of diclofenac into the skin, penetration into underlying muscles (2-3 cm beneath the skin's surface), and limited systemic bioavailability or distribution of diclofenac to other tissues beyond the immediate patch application site. Diclofenac concentrations on the right-dorsal side were comparable among animals treated with the dermal and oral routes of administration, showing that sufficient diclofenac exposure was achieved in muscles with the dermal patch relative to an efficacious oral dose of $50 \mathrm{mg}$. Low concentrations of diclofenac were observed in skin and muscle biopsies from the left (untreated) side of animals receiving the dermal patch. These results show that the muscle concentrations are due to direct drug absorption from the dermal patch and penetration to muscles rather than to delivery through systemic circulation. Physicochemical properties of the epolamine salt formulation of diclofenac used in the patch may act to enhance local tissue penetration; the epolamine salt is more soluble in both water and nonpolar solvents than other diclofenac salts, and also demonstrates surfactant behavior that may increase membrane permeability. ${ }^{21}$

The PK data from the present study and previous evaluations in human subjects are largely supportive of the clinical data that have demonstrated the effectiveness of the diclofenac epolamine patch in the treatment of soft-tissue injuries, coupled with an acceptable safety and tolerability profile., ${ }^{4,8,22}$ Using a relevant animal model, this study directly demonstrated the low systemic absorption and high tissue penetration of diclofenac by dermal patch application compared with oral administration. Topical formulations such as the diclofenac epolamine patch may represent an effective and well-tolerated alternative for the treatment of soft-tissue injury.

\section{Acknowledgments}

The authors would like to thank Doug Rickert and CiToxLAB Group (formally LAB Research North American Inc) for their contribution to the study.

This study was sponsored by Pfizer Inc. Editorial support was provided by $\mathrm{C}$ Campbell, $\mathrm{PhD}$, of PAREXEL, and was funded by Pfizer Inc.

\section{Authorship contributions}

Susanna Tse contributed to the analysis and interpretation of the data, and is the primary author responsible for the manuscript. Kendall D Powell contributed to the analysis and interpretation of the data, and critical revision of the manuscript. Stephen MacLennan, Allan R Moorman and Craig Paterson contributed to the design of the study and critical revision of the manuscript. Rosonald Bell contributed to the interpretation of the data and critical revision of the manuscript. All authors gave final approval of the version to be published.

\section{Disclosure}

Susanna Tse is an employee of Pfizer Inc. Kendall D Powell is an employee of Tandem Labs, A LabCorp Company. Stephen MacLennan is an employee of BioCryst Pharmaceuticals Inc. Allan R Moorman was an employee of Pfizer Inc (legacy King Pharmaceuticals, Inc) at the time of the study; he is currently an employee of Alta Vetta Pharmaceutical Consulting, LLC. Craig Paterson is an employee of Salix Pharmaceutical, Inc. Rosonald Bell is an employee of Pfizer Inc.

The authors report no other conflicts of interest in this work.

\section{References}

1. McCarberg BH, Argoff CE. Topical diclofenac epolamine patch 1.3\% for treatment of acute pain caused by soft tissue injury. Int J Clin Pract. 2010;64(11):1546-1553.

2. Bookman AA, Williams KS, Shainhouse JZ. Effect of a topical diclofenac solution for relieving symptoms of primary osteoarthritis of the knee: a randomized controlled trial. CMAJ. 2004;171(4):333-338.

3. Stanos SP. Topical agents for the management of musculoskeletal pain. J Pain Symptom Manage. 2007;33(3):342-355.

4. Lionberger DR, Brennan MJ. Topical nonsteroidal anti-inflammatory drugs for the treatment of pain due to soft tissue injury: diclofenac epolamine topical patch. J Pain Res. 2010;3:223-233.

5. Petersen B, Rovati S. Diclofenac epolamine (Flector) patch: evidence for topical activity. Clin Drug Investig. 2009;29(1):1-9.

6. Rainsford KD, Kean WF, Ehrlich GE. Review of the pharmaceutical properties and clinical effects of the topical NSAID formulation, diclofenac epolamine. Curr Med Res Opin. 2008;24(10):2967-2992.

7. Galer BS, Rowbotham M, Perander J, Devers A, Friedman E. Topical diclofenac patch relieves minor sports injury pain: results of a multicenter controlled clinical trial. J Pain Symptom Manage. 2000;19(4): 287-294.

8. Lionberger DR, Joussellin E, Lanzarotti A, Yanchick J, Magelli M. Diclofenac epolamine topical patch relieves pain associated with ankle sprain. J Pain Res. 2011;4:47-53.

9. Banning M. Topical diclofenac: clinical effectiveness and current uses in osteoarthritis of the knee and soft tissue injuries. Expert Opin Pharmacother. 2008;9(16):2921-2929.

10. Qvist MH, Hoeck U, Kreilgaard B, Madsen F, Frokjaer S. Evaluation of Göttingen minipig skin for transdermal in vitro permeation studies Eur J Pharm Sci. 2000;11(1):59-68.

11. Bansal S, DeStefano A. Key elements of bioanalytical method validation for small molecules. AAPS J. 2007;9(1):E109-E114. 
12. Shah VP, Midha KK, Findlay JW, et al. Bioanalytical method validationa revisit with a decade of progress. Pharm Res. 2000;17(12): 1551-1557.

13. Viswanathan CT, Bansal S, Booth B, et al. Quantitative bioanalytical methods validation and implementation: best practices for chromatographic and ligand binding assays. Pharm Res. 2007;24(10): 1962-1973.

14. Food and Drug Administration. Guidance for Industry: Bioanalytical Method Validation. US Department of Health and Human Services, FDA, Center for Drug Evaluation and Research; 2001. Available from: http://www.fda.gov/downloads/Drugs/GuidanceComplianceRegulatory Information/Guidances/UCM070107.pdf. Accessed June 5, 2012.

15. Gibaldi M, Perrier D. Pharmacokinetics. New York: Marcel Dekker Inc; 1975.

16. Oberle RL, Das H, Wong SL, Chan KK, Sawchuk RJ. Pharmacokinetics and metabolism of diclofenac sodium in Yucatan miniature pigs. Pharm Res. 1994;11(5):698-703.

17. Bode G, Clausing P, Gervais F, et al; for Steering Group of the RETHINK Project. The utility of the minipig as an animal model in regulatory toxicology. J Pharmacol Toxicol Methods. 2010;62(3):196-220.
18. Gschwend MH, Martin W, Arnold P, et al. Determination of the transdermal bioavailability of a newly developed diclofenac sodium patch in comparison with a reference preparation. Arzneimittelforschung. 2005;55(7):403-413.

19. Heyneman CA, Lawless-Liday C, Wall GC. Oral versus topical NSAIDs in rheumatic diseases: a comparison. Drugs. 2000;60(3):555-574.

20. Singh P, Roberts MS. Skin permeability and local tissue concentrations of nonsteroidal anti-inflammatory drugs after topical application. J Pharmacol Exp Ther. 1994;268(1):144-151.

21. Fini A, Fazio G, Gonzalez-Rodriguez M, Cavallari C, Passerini N, Rodriguez L. Formation of ion-pairs in aqueous solutions of diclofenac salts. Int J Pharm. 1999;187(2):163-173.

22. Jenoure P, Segesser B, Lühti U, Gremion G. A trial with diclofenac HEP plaster as topical treatment in minor sport injuries. Drugs Exp Clin Res. 1993;19(3):125-131.
Journal of Pain Research

\section{Publish your work in this journal}

The Journal of Pain Research is an international, peer-reviewed, open access, online journal that welcomes laboratory and clinical findings in the fields of pain research and the prevention and management of pain. Original research, reviews, symposium reports, hypothesis formation and commentaries are all considered for publication.

\section{Dovepress}

The manuscript management system is completely online and includes a very quick and fair peer-review system, which is all easy to use. Visit http://www.dovepress.com/testimonials.php to read real quotes from published authors. 